\title{
Effect of chitosan concentration on the rheological properties of acetic and lactic acid solutions
}

\author{
Clara A. Tovar, M. Carmen Gómez-Guillén, M. Pilar Montero
}

\begin{abstract}
Chitosan $(\mathrm{Ch})$ is a biodegradable cationic polymer, with industrial interest. The purpose of this study was to analyse the effect of Ch concentration (1$3 \%$ ), on the rheological properties of acetic (A1-A3) and lactic (L1-L3) acid solutions. Flow curves (up-down) at $20^{\circ} \mathrm{C}$, provided the consistency $(\kappa)$ and the flow index $(n)$. In all solutions, $\kappa$ increased and $n$ decreased with $\mathrm{Ch}$ concentration. For L3, greater $\kappa$ value and lower $n$ exponent indicate stronger shear thinning response. The structural-breaking rate $\left(\mathrm{v}_{\mathrm{up}}\right)$, and the regeneration rate $\left(\mathrm{v}_{\text {down }}\right)$ were proposed as a measurement of the time dimension in the shear thinning response.
\end{abstract}

\section{Introduction}

Chitosan $(\mathrm{Ch})$ is a non-toxic cationic polymer, which has been received interest in the pharmaceutical and food industry because of its functional properties [1], which are dependent on the $\mathrm{pH}$ and type of acid in which it is dissolved. The replacement of acetic by lactic acid for Ch solutions may be advantageous to avoid the odour associated to the former, however, it might modify the rheological behaviour. It has been observed that in the preparation of $\mathrm{Ch}$ films, the addition of plasticizing agents is not necessary when the $\mathrm{Ch}$ is solubilized in lactic acid, which can constitute an extra benefit [2]. The objective of this work was to evaluate: 1) the effect of the (lactic and acetic) acid solutions on the flow response at several Ch concentrations. 2) The potential applications of two acids as a function of $\mathrm{Ch}$ concentration.

\section{Material and methods}

Chitosan (deacetylation degree 90.7\%; molecular weight 140,000 Da) from Guinama (Valencia, Spain), was dissolved in acetic acid solutions at 1\% (w/v) (A1, $\mathrm{pH}=3.50), 2 \%(\mathrm{w} / \mathrm{v})(\mathrm{A} 2, \mathrm{pH}=3.79)$ and $3 \%(\mathrm{w} / \mathrm{v})(\mathrm{A} 3, \mathrm{pH}=3.98) \mathrm{Ch}$ concentration. Similarly with $1 \%(\mathrm{w} / \mathrm{v})(\mathrm{L} 1, \mathrm{pH}=3.20), 2 \%(\mathrm{w} / \mathrm{v})(\mathrm{L} 2, \mathrm{pH}=4.06)$ and $3 \%$ $(\mathrm{w} / \mathrm{v})(\mathrm{L} 3, \mathrm{pH}=5.52) \mathrm{Ch}$ in lactic acid solutions under stirring overnight at room temperature $\left(20^{\circ} \mathrm{C}\right)$.

Rheological tests were performed with RS600 Haake rheometer (Thermo Electron Corp. Karlsruhe, Germany) and the cone-plate (CP35/2 with $0.105 \mathrm{~mm}$ gap). All measurements were made at $20.0 \pm 0.1{ }^{\circ} \mathrm{C}$. The viscoelastic properties were analysed by time sweeps ( $5400 \mathrm{~s}, 0.1 \mathrm{~Hz}$ and $\gamma=0.4 \%$ ). Flow curves were obtained using four intervals: 1) pre-shear phase $\left.\left(30 \mathrm{~s}^{-1}, 10 \mathrm{~min}\right) ; 2\right)$ up ramp $\left(300 \rightarrow 900 \mathrm{~s}^{-1}\right.$; $10 \mathrm{~min}$.); 3) high rate interval (900 $\left.\mathrm{s}^{-1}, 5 \mathrm{~min}.\right)$; 4) down ramp $\left(900 \rightarrow 300 \mathrm{~s}^{-1} ; 10\right.$

\section{C.A. Tovar}

Department of Applied Physics, Faculty of Sciences, University of Vigo, As Lagoas s/n, 32004

Ourense, (Spain) e-mail: tovar@uvigo.es

M.C. Gómez-Guillén

Department of Products, Institute of Food Science, Technology and Nutrition (ICTAN-CSIC),

C/José Antonio Novais, 10, 28040 Madrid, (Spain) e-mail: cgomez@ictan.csic.es

M.P. Montero

Department of Products, Institute of Food Science, Technology and Nutrition (ICTAN-CSIC),

C/José Antonio Novais, 10, 28040 Madrid, (Spain) e-mail: mpmontero@ictan.csic.es 
$\min )$. The thixotropy was examined by the step test with three steps: 1) reference $\left(100 \mathrm{~s}^{-1}, 90 \mathrm{~s}\right)$; 2) high shear-rate $\left.\left(1000 \mathrm{~s}^{-1}, 45 \mathrm{~s}\right) ; 3\right)$ regeneration $\left(100 \mathrm{~s}^{-1}, 600 \mathrm{~s}\right)$. Statistical analysis: data are presented as mean values of five replicates and were tested with expanded uncertainty limits (EUL). Trends were considered significant when means of compared sets differed at $\mathrm{p}<0.05$ (Student's t-test).

\section{Results and Discussion}

\subsection{Time dependence of the oscillatory measurements}

$G$ ' and $G$ '” were practically time independent and data were means of the instantaneous values considering the testing times and the number of test repetitions. All solutions exhibited fluid-like behaviour with phase angle $\left(\delta>50^{\circ}\right)$. At fixed $\mathrm{Ch}$

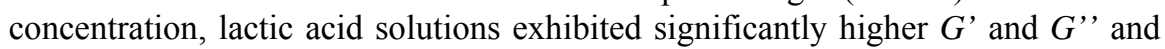
lower $\delta$ values $(\mathrm{p}<0.05)$ than in acetic solution (Table 1$)$, showing a more "fluid strength". This result shows the greater stabilising role of lactic acid with $\mathrm{Ch}$ chains, principally by hydrogen bonding and polar interactions, in line with the plasticizer effect shown of Ch films [2].

Table 1 Viscoelastic parameters (Pa) of different acid solutions at $0.1 \mathrm{~Hz}$ and $20^{\circ} \mathrm{C}$

\begin{tabular}{lllllll}
\hline & A1 & L1 & A2 & L2 & A3 & L3 \\
\hline$G^{\prime}$ & $0.10 \pm 0.01^{\mathrm{b}}$ & $0.17 \pm 0.03^{\mathrm{c}}$ & $0.0173 \pm 0.003^{\mathrm{a}}$ & $0.53 \pm 0.09^{\mathrm{e}}$ & $0.38 \pm 0.05^{\mathrm{d}}$ & $0.93 \pm 0.14^{\mathrm{f}}$ \\
$G^{\prime \prime}$ & $0.15 \pm 0.01^{\mathrm{a}}$ & $0.25 \pm 0.04^{\mathrm{b}}$ & $0.164 \pm 0.004^{\mathrm{a}}$ & $0.97 \pm 0.12^{\mathrm{c}}$ & $1.11 \pm 0.08^{\mathrm{d}}$ & $2.11 \pm 0.09^{\mathrm{e}}$ \\
$\delta\left(^{\circ}\right)$ & $59.0 \pm 2.7^{\mathrm{b}}$ & $53.0 \pm 3.2^{\mathrm{a}}$ & $84.25 \pm 0.79^{\mathrm{e}}$ & $65.5 \pm 2.8^{\mathrm{c}}$ & $73.5 \pm 1.4^{\mathrm{d}}$ & $68.9 \pm 2.4^{\mathrm{c}}$ \\
\hline
\end{tabular}

${ }^{\mathrm{a}-\mathrm{f}}$ different letters in the same column indicate significant differences $(\mathrm{p}<0.05)$.for each parameter

The greater differences were found at $2 \% \mathrm{Ch}$ (Table 1), suggesting that L2 solution is a more complex and structured fluid comparing with A2. For L3, a similar result was found, but naturally with higher $G^{\prime}$ and $G$ ', moduli (Table 1). At higher $\mathrm{Ch}$ concentration, there are more entanglements producing a denser fluid.

\subsection{Flow curves}

Flow curves were shown in terms of the apparent viscosity $(\eta)$ vs shear rate $(\gamma)$ (eq. 1).

$$
\eta=\kappa \cdot \gamma^{n-1}
$$

Being $\kappa$ the consistency, and $n$ the flow index [3]. $\kappa$ values increased with increasing Ch concentration, being similar in up and down curves, except for L3, since down- $\kappa>$ up- $\kappa$ (Fig. 1a). This result indicates greater structural regeneration ability with decreasing shear rate (L3).

At fixed Ch concentration ( $2 \%$ and $3 \%$ ), the $\kappa$ coefficient was higher in L2 vs A2 and in L3 vs A3, showing a greater packing level in lactic vs acetic acid solutions. In A1 and L1 $n$ parameter was around 0.93 (Newtonian response), since $\eta$ was practically shear independent. At higher $\mathrm{Ch}$ concentrations, $n$ values decreased being the lowest in L3. In addition, down- $n<$ up- $n$ (Fig. 1b), low $n$ values 
indicate a shear thinning behaviour. So, when the shear rate increases, the viscosity decreases, since the molecular friction between fluid layers decreases, thus, the Ch chains might be aligned in the shear direction, reducing the flow resistance [3].
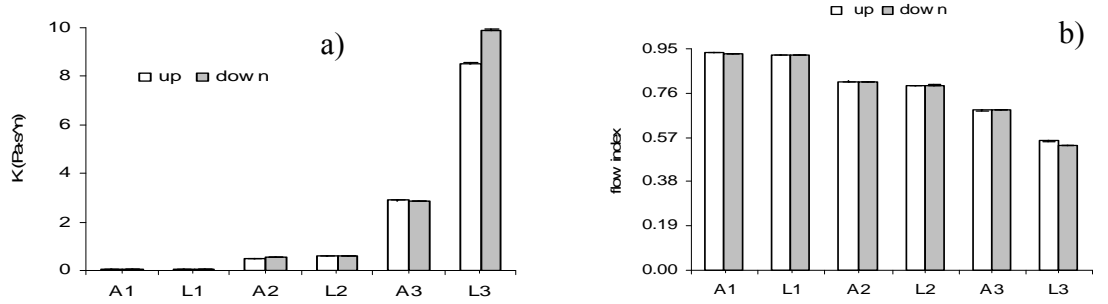

Fig. 1 Influence of the chitosan concentration in acetic and lactic acid solutions on the consistency (к) (a) and flow index (n) (b). $\mathrm{T}=20^{\circ} \mathrm{C}$

In general $\eta$ values can be linearly fitted with time (eq. 2). From the absolute value of the slope (b) (up and down curves), can be obtained the structural disruption and regeneration rate respectively (Table 2). Thus, $b$ slope quantifies the temporal dimension of the "shear-thinning", phenomenon dependent on the colloidal structures [3]. So, a complex fluid is a more shear sensible and $\eta$ is faster reduced (up-curve) being a shear-reversible effect due to the physical nature of the intermolecular interactions. Thus, in the down-curve new structural rearrangements in "chitosan- acids-water" complex produced a specific re-construction of the inner structure [4] based on the type of acid and Ch concentration.

$$
\eta=\eta_{0}+b \cdot t
$$

Table 2 Rate of the structural disruption (up) and regeneration (down) for A1-A3 and L1-L3 solutions. $\mathrm{T}=20^{\circ} \mathrm{C}$

\begin{tabular}{|c|c|c|c|c|c|c|}
\hline Sample & A1 & $\mathrm{L} 1$ & A2 & L2 & A3 & L3 \\
\hline $\mathrm{Up}-\mathrm{b}(\mu \mathrm{Pa})$ & $-4.415 \pm 0.004^{\mathrm{aA}}$ & $-4.81 \pm 0.01^{\mathrm{aB}}$ & $-49.6 \pm 0.4^{\mathrm{aC}}$ & $-57.4 \pm 0.5^{\mathrm{aD}}$ & $-212.87 \pm 3.6^{\mathrm{aE}}$ & $\begin{array}{l}\mathrm{b}+2 \mathrm{ct}(\mu \mathrm{Pa}) \text { up } \\
-663+0.93 \mathrm{t}\end{array}$ \\
\hline Down-b $(\mu \mathrm{Pa})$ & $4.666 \pm 0.008^{\mathrm{bA}}$ & $5.01 \pm 0.02^{\mathrm{bB}}$ & $50.6 \pm 0.4^{\mathrm{bC}}$ & $57.3 \pm 0.6^{\mathrm{aD}}$ & $210.1 \pm 3.0^{\mathrm{aE}}$ & $\begin{array}{l}\mathrm{b}+2 \mathrm{ct}(\mu \mathrm{Pa}) \text { down } \\
125+0.95 \mathrm{t}\end{array}$ \\
\hline
\end{tabular}

a-b- different small letters indicate significant differences $(\mathrm{p}<0.05)$ between up and down curves; ${ }^{\mathrm{A}-\mathrm{E}-}$ different capital letters indicate significant differences $(\mathrm{p}<0.05)$ between $\mathrm{A} 1-\mathrm{A} 3$ and $\mathrm{L} 1-\mathrm{L} 2$ samples.

In acetic acid solutions the $b$ slopes were similar in up vs down ramps. The $b$ slope was significantly $(\mathrm{p}<0.05)$ higher in A3 $\rightarrow$ A2 $\rightarrow$ A1. Similarly occurs in L1 and L2 (Table 2). At fixed Ch concentration ( $1 \%$ and $2 \%$ ), $b$ values were lower in acetic than in lactic acid solutions (Table 2). This fact could be related to the greater steric impediments in the acetic solutions due to the methyl groups in a shorter molecular chains (A1 and A2). The repulsive forces could reduce the "fluid strength" in A1 vs L1 and in A2 vs L2 (Table 1). L3 exhibited a quadratic dependence of $\eta v s \mathrm{t}$ (eq. 3). Hence, the first derivative is a time-linear function 
whose down-slope (rate of structural regeneration) was higher than the up-slope (structural disruption) (Table 2).

$$
\eta=\eta_{0}+b \cdot t+c \cdot t^{2}
$$

This trend suggests that $\mathrm{L} 3$ exhibited higher number of the associating sites in the recovery process, comparing with those at the initial state. This fact could be related to the bioadhesive role in the pharmaceutical industry.

\subsection{Step test with three intervals}

The possible thixotropy was examined using the step test with three intervals. For all solutions viscosities at constant shear rate for each step were time independent, irrespective of the shear rate value. Hence, there was not thixotropy in any case (Fig. 2). It might be calculated the percentages of the structural regeneration (SR), considering the relative increase of the viscosity, from $\eta(t=135 \mathrm{~s})$ to $\eta(\mathrm{t}=750 \mathrm{~s})$ (eq. 4). For $1 \% \mathrm{Ch}, \% \mathrm{SR}$ were $12 \%$ (A1) and $14 \%$ (L1). This percentage was increased with increasing the Ch concentration, being similar in A2 (40\%) vs L2 $(44 \%)$. However at $3 \% \mathrm{Ch}$, there were differences between \%SR in A3 (88\%) and L3 (280\%), in line with the greater b-slopes (Table 2). So, lactic acid promotes the formation of greater amount of intermolecular hydrogen bonds without steric effects enhancing the molecular reconstruction ability in L3 solution.

$$
\% S R=\frac{\left(\eta_{750}-\eta_{135}\right) \cdot 100}{\eta_{135}}
$$

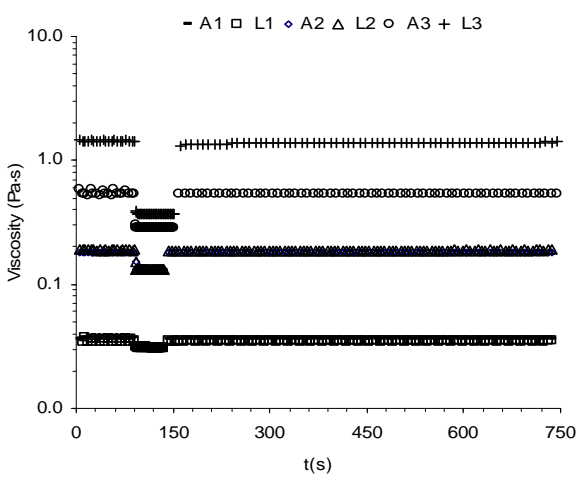

Fig. 2 Influence of the Chitosan concentration and type of acid on the viscosity $\left(100 \mathrm{~s}^{-1}, 1000 \mathrm{~s}^{-1}\right.$ and $\left.100 \mathrm{~s}^{-1}\right) . \mathrm{T}=20^{\circ} \mathrm{C}$

Acknowledgments This work has been financed by the Spanish MINECO under Project AGL2017-84161 co-funded with EU-Regional Development Fund.

\section{References}

1. R.C.F. Cheung,. T.B. Ng, J.H., Wong, W.Y. Chan, Mar. Drugs, 8 (2015)

2. M.Y. Arancibia,.A. Alemán, M.M. Calvo, M.E. López-Caballero, P. Montero, M.C. GómezGuillén, Food Hydrocoll. 23 (2014)

3. Figura, L.O., Teixeira, A.A.. Food Physics. (Springer-Verlag, Heidelberg, 2007), p. 149-152

4. Larson, R.G. The Structure and Rheology of Complex Fluids, (Oxford University Press, New York, 1999), p.12-15. 